\title{
PENGGAJIAN PEGAWAI KANTOR
}

\author{
Oleh : \\ Joko Kumoro
}

\section{Abstrak}

Efisiensi kerja dapat direalisasikan secara baik apabila dalam diri pegawai terkandung keinginan kerja, kemampuan kerja dan kemahiran kerja. Keinginan bekerja merupakan faktor yang dapat dilakukan interensi oleh organisasi melalui berbagai insentif, seperti ; gaji yang layak, jaminan kesehatan, perumahan, hari tua, dan kontra prestasi lainnya.

Gaji merupakan bentuk insentif yang kompleks, pelik, sensitif dan fleksibel. Ketidaktepatan dalam penentuan besaran dan tingkat gaji akan memunculkan berbagai reaksi baik yang konstruktif maupun destruktif. Penentuan gaji secara baik harus didukung adanya data tentang evaluasi jabatan secara benar. Ada berbagai metode evaluasi jabatan yaitu: (1) Job ranking; (2) jab grading; (3) Comparison factor; (4) Point system dan sebagainya.

Jabatan/pekerjaan kantor merupakan kegiatan yang memiliki ciri : sukar diukur, banyak menuntut kerja mental, tidak ada ukuran baku secara ketat maka metode Point system dinilai tepat. Point system dipandang cocok karena metode ini mampu mengurai faktor pekerjaan menjadi sub-sub faktor dan derajat dalam setiap jabatan

\section{Pendahuluan}

Gaji merupakan bentuk kompensasi penting dalam kehidupan modern. Oleh karena itu bekerja pada umumnya memperoleh gaji yang layak dan adil. Banyak ungkapan ketidakpuasan yang diwujudkan dalam bentuk unjuk rasa, pemogokan bahkan sampai tindakan yang destruktif, dipicu oleh ketidakpuasan dalam penggajian. Ketidakpuasan yang belum sempat muncul ke permukaan dapat memiliki dampak pada aspek lain, seperti : keinginan bekerja rendah, mangkir, absensi, boros waktu dan perilaku menyimpang lainnya. Oleh karena itu perlu selalu dipikirkan, direncanakan dan diimplementasikan teknik penggajian yang mampu memenuhi harapan sebagian besar pegawai.

Teknik penggajian ketepatan besaran dan tingkatan gaji yang diberikan terhadap suatu jabatan/ pekerjaan sangat ditentukan metode evaluasi jabatan. Ada beberapa macam cara yang dapat dilakukan un- 
tuk menilai suatu jabatan yaitu : (1) analitis; dan (2) non-analitis. Tanpa adanya evaluasi jabatan yang baik tidak dapat diharapkan karya terbaik karyawan dapat dimunculkan. Berkaitan dengan hal ini, perlu selalu diusahakan bahwa evaluasi terhadap setiap pekerjaan/jabatan dikantor dengan cara-cara yang benar/tepat.

\section{Faktor Efisiensi Kerja}

Efisiensi merupakan jiwa dan semangat yang harus selalu melekat pada diri pegawai dalam melaksanakan tugas. Efisiensi dapat dimanifestasikan dalam beberapa bentuk seperti produktifitas, karya terbaik, dan berbagai ukuran lain. Cara kerja yang efisien perlu selalu dipikirkan, direncanakan dan dilaksanakan oleh semua pegawai pada semua tingkat mulai pucuk pimpinan sampai pegawai paling rendah. Menurut Werther dan Davis (1993) dalam Miriam Sjofjan Arif (2000:60) "Strategi yang dipergunakan untuk memperbaiki dan meningkatkan produktifitas terfocus pada investasi dalam bidang sumber daya manusia, disamping investasi usaha dan teknologi baru". Investasi dalam bidang Sumber Daya Manusia terutama melakukan perubahan hubungan kekaryawanan (employee relations). Hubungan antara karyawan dengan pimpinan, karyawan dengan majikan untuk meningkatkan efisiensi organisasi dapat diarahkan pada pendekatan perbaikan kualitas hidup pe- gawai (Quality of Work lifo/QWL) Bentuk nyata dari QWL menumui Werther dan Davis borupa; "вuper visi yang wajar, kondisi kerja yang menyenangkan, imbalan dan benelil yang wajar, pekerjaan yang menarik dan menantang" (Mirriam Sofjan, 2000 : 60). Gaji, upah walaupun bu kan satu-satunya faktor yang mem. pengaruhi efisiensi korja lelapl me. rupakan faktor yang cukup penling dan strategis.

Beberapa faktor yang dapal mempengaruhi efisionsi kerja yallu Suasana kerja, alat, ruangan, ling kungan fisik, metodo dan diil pega wai itu sendiri. Pogawal yang beker|a secara efisien mampu mentherlkan! karya terbaik bagi poncapalan li|uan organisasi. Socara intenn dalanll diil pegawai harus dapat diperillil bebe rapa prasyarat agar bekenja elisien The Liang Gie mongidentifikasikan ada 3 syarat yang harus molokal pa da diri pegawai untuk dapal bekarja secara efisien, yaitu: "(1) koinginan bekerja; (2) komampuan bekerja, dan (3) kemahiran bokorja", 12000 44). Sedangkan Kallans dan Kaoling mengidentifikasikan faklor diil peua wai yang mompongamill moulukll vitas kantor molipuli: "(1) Worker skill and knowlodgo, (2) work bella vior, : needs, allifudos, molivalion" (1987:407) pogawal maningakan faktor kunci dalam mowillulkall ofi

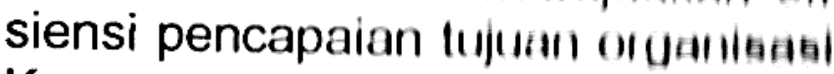
Kemampuan bokorja pouawal ill tentukan oleh tingkal koselialail (liil 
dalam kehidupan sehari-hari. Oleh karena itu kemampuan kerja merupakan faktor yang relatif sulit untuk dilakukan intervensi oleh organisasi sebab berkaitan dengan pola hidup, kebiasaan, latar belakang dan kesukaan yang bersifat individual. Kemahiran kerja dapat dicapai melalui pendidikan baik yang bersifat formal maupun latihan yang bersifat non formal serta pengalaman personal yang pernah dialami. Peningkatan kemahiran kerja relatif lebih mudah dilakukan intervensi oleh organisasi. Faktor lain dalam diri pegawai yang cukup penting menentukan efisiensi kerja yaitu keinginan bekerja. Keinginan bekerja menjadi kuat karena hadirnya motivasi dan rangsangan (insentif). Karya terbaik akan diberikan oleh pegawai terhadap organisasi apabila dalam diri pegawai terkandung kemampuan, kemahiran, dan keinginan.

\section{Gaji dan Keinginan Kerja}

Gaji dengan berbagai sebutan, bentuk dan jenis merupakan perangsang yang secara umum dapat diterima untuk menghadirkan keinginan bekerja. Pada dasarnya pegawai memiliki keinginan bekerja kuat karena ada harapan memperoleh penghasilan berupa gaji. Menurut Abraham H. Maslow (1954) bahwa gaji merupakan kebutuhan yang paling dasar, yaitu kebutuhan fisiologis.
Kebutuhan fisiologis : kebutuhan akan makan, minum. tempat tinggal dan bebas dari rasa sakit : dengan kata lain kebutuhan fisiologis ini terdiri kebutuhan terhadap pangan. sandang, papan, dan kesehatan. Untuk dapat memenuhi kebutuhan tersebut seseorang membutuhkan pendapatan atau gaji yang memadai.

Teori Maslow ini memang telah banyak dikritik, tetapi kenyataan terpenuhinya kebutuhan fisiologis ini sebagai dasar untuk mencapai kebutuhan yang lebih tinggi. Pada masyarakat modern seperti sekarang ini pengaruh dunia barat cukup dominan mendorong gaji merupakan bentuk kompensasi yang penting dan fleksibel. Gaji yang dirasakan adil. memadai, cukup, dapat dimengerti merupakan daya dorong yang maha hebat bagi karya terbaik pegawai. Berdasarkan penelitian yang dilakukan oleh Miriam Sofjan Arif pada PT Sinar Meadow, perusahaan produsen minyak Filma membuktikan bahwa unsur-unsur QWL (Quality of Work Life) seperti : "Supervisi yang positif, komunikasi yang harmonis. partisipasi karyawan dan kepeduliannya terhadap organisasi dan kondisi kerja yang menyenangkan telah terlaksana di Perusahaan PT Sinar Meadow Internasional Indonesia. Harga satu unsur imbalan masih dirasakan kurang" (2000:62). 
Persoalan gaji bukan merupakan masalah yang sederhana. Dari sekian faktor $\mathrm{QWI}$ ternyata imbalan atau gaji merupakan unsur yang dirasakan belum dapat terpenuhi secara baik. Organisasi dalam bentuk apapun dituntut dapat merencanakan dan menyusun program penggajiàn yang memuaskan sebagian besar pegawai. Banyak kasus pemogokan, pengrusakan karena didorong ketidakpuasan terhadap penggajian. Hal ini selaras dengan pernyataan Bob Waworuntu (2000 :63) dalam jurnal Bisnis dan Birokrasi sebagai berikut:

Walaupun gaji bukan segalanya dan bukan satu-satunya konsep yang paling penting dalam hubungan ketenagakerjaan, tetapi gaji selalu menjadi salah satu sumber utama konflik dalam hubungan kerja, yang semuanya bermuara pada rasa ketidakadilan dan atau ketidakpuasan. Dengan demikian setiap organisasi dituntut mampu menciptakan sistem penggajian yang dapat mencegah reaksi yang tidak membangun (destructive). Penggajian yang tepat mampu meningkatkan kinerja efisiensi dan moral pegawai.

Pentingnya gaji agar membangkitkan kinerja yang konstruktif dan positif juga dikemukakan oleh Quible (1984:31) sebagai berikut : Assuring employees that they are receiving an equitable salary has a positive impact on their efficiency and morale.

\section{Gaji Kompensasi Populer}

Gaji merupakan bentuk kompensasi/kontra prestasi yang paling populer dewasa ini. Banyak unjuk rasa yang menggambarkan ketidak= puasan karyawan pada umumnya terkait dengan gaji. Pada zaman modern ini gaji rangsangan yang mam= pu membangkitkan motivasi cukup kuat bagi pegawai untuk dapat memberikan karya terbaik. Hal ini selaras dengan pernyataan Ahmad S Ruky $(2002$; 188) sebagai berikut

........ di negara seperti Indonesia dimana tingkat upah dan gaji terutama pada karyawan dan pekerja tidak terampil dan semi torampil masih sangat rendah, penghargaan dalam bentuk uang tunal masih tetap dihargai daripada bentuk lain. Adalah sebuah fakta yang terjadi di banyak perusahaan bahwa cuti tahunanpun kalau bisa ingin diganti dengan uang. Penghargaan berupa cincin emas atau gelang emas sebagai tanda kesetiaan pada perusahaanpun dijual ketoko untuk memperoleh uang tunai.

Kata kunci dalam penggajian yang utama adalah gaji yang diterimakan dirasa layak dan adil. Kola. yakan besaran gaji harus diukur dari beberapa aspek seperti : (1) kebu= tuhan hidup; (2) kemampuan mom: bayar; dan (3) besaran gaji oraga= nisasi lain. Karyawan bekerja mini. mal mampu memenuhi kebutuhan hi: dup yang mendasar berupa 
pangan, sandang dan papan (kebutuhan fisiologis Maslow). Oleh karena itu calon pegawai atau pelamar pekerjaan akan terkejut menghadapi pertanyaan pertanyaan besaran gaji yang diminta pada waktu seleksi. Gaji yang diterima harus mampu memenuhi kebutuhan hidup di daerah tersebut. Di Indonesia, tiap-tiap daerah memiliki UMR (upah minimun regional) yang berbedabeda merupakan cerminan kebutuhan hidup di satu wilayah. Kemampuan membayar gaji bagi organisasi terkait dengan perkembangan yang dicerminkan pada pendapatan atau keuntungan. Adanya kecenderungan pendapatan yang selalu meningkat dari tahun ketahun bagi suatu organisasi menunjukan kekuatan membayar yang baik. Perhatian terhadap besaran gaji yang akan diterimakan kepada pegawai tentu perlu membandingkan dengan pasar gaji yang berlaku dilingkungan. Kondisi ini akan mampu menekan perpindahan (labour turn over) maupun kooptasi pegawai oleh organisasi lain, terutama pesaing. Perpindahan dan kooptasi pegawai yang terlalu tinggi tidak banyak menguntungkan sebab akan terjadi pemborosan dalam pengembangan sumber daya manusia.

Keadilan dalam menentukan besaran gaji antar pegawai sangat mempengaruhi keinginan bekerja. Pimpinan, manajer, kepala atau apapun sebutan lainnya perlu memperhatikan konsistensi dalam peng- gajian. Dalam kaitan dengan keadilan penggajian Indonesia telah meratifikasi konvensi ILO (International Labour Organization) nomor 100 yang menetapkan tidak ada diskriminasi dalam pengupahan untuk pekerjaan yang memiliki nilai yang sama. Kemampuan penentuan gaji secara adil dapat direalisasikan dengan memilih metode evaluasi jabatan yang tepat

\section{Evaluasi Jabatan dan Gaji}

Evaluasi jabatan merupakan proses yang menghasilkan bobot dan nilai sesuatu jabatan/pekerjaan. Bobot antar jabatan ini perlu dirumuskan secara memuaskan agar konsistensi internal dan eksternal dalam penggajian dapat tercapai. Konsistensi internal akan memberikan gambaran konsep penggajian relatif dalam intern organisasi. Sedangkan konsistensi eksternal berkaitan dengan tingkat relatif struktur penggajian yang diinginkan organisasi dibandingkan dengan struktur gaji yang ada di industri, masyarakat maupun negara. Berkaitan dengan bobot jabatan dan gaji ini Achmad S. Ruky membuat kesimpulan tentang "nilai yang sama" menurut konvensi ILO (International Labour Organization) sebagai berikut :

Pekerjaan-pekerjaan yang mempunyai "nilai" atau "bobot" (value) yang sama harus mendapat imbalan yang sama. Sebaliknya, dari konvensi ini dapat disimpulkan bah- 
wa yang harus menjadi dasar untuk menetapkan apakah dua atau beberapa jabatan dinyatakan mempunyai "nilai/bobot" yang sama bukan hanya tingkat pendidikan formal yang dimiliki oleh orang yang melakukannya atau masa kerjanya, tetapi harus juga dinilai faktor-faktor lain yang relevan. (2002: 71).

\section{Evaluasi jabatan}

“.........bertujuan menentukan nilai relatif dalam arti berat ringannya suatu pekerjaan dibandingkan dengan pekerjaan-pekerjaan yang lain dalam sebuah organisasi" (Ahmad S Ruky, 2002 : 72). Menurut Heidjrachman Ranupandojo dan suad husnan (1995 : 141) evaluasi jabatan merupakan usaha untuk menentukan dan membandingkan nilai suatu jabatan tertentu dengan nilai jabatan-jabatan lain yang ada dalam organisasi. Sedangkan Hani Handoko mempergunakan istilah evaluasi pekerjaan yang berarti berbagai prosedur sistematik untuk menentukan nilai relatif pekerjaan-pekerjaan" (1997 : 165)

Evaluasi jabatan dapat dilaksanakan secara kasar maupun dilakukan secara cermat dengan perhitungan-perhitungan yang sangat teli ti. Ada 4 macam metode evaluasi jabatan menurut Hani Handoko (1997) : Heidrachman Ranupandojo dan Suad Husnan (1995); Komarudin (1985) yaitu : (1) Job ranking; (2) Job Grading; (3) Factor Comparison; dan (4) Point System. Sementara itu metode evaluasi jabatan yang lebih terrinci dikemukakan oleh Achmad S Ruky (2002) yaitu : (1) metode non analitis, dan (2) metode analitis. Masing- masing klasifikasi dirinci lagi menjadi beberapa metode yang lebih detail. Metode non analitis terdiri atas: (1) metode mengikuti hierarchi dalam skema organisasi; (2) metodo Forced ranking; (3) metode klasifikasi jabatan; (4) metode factor comparison dan (5) metode yang dipergunakan oleh pegawai negeri (sipil labri). Sedangkan metode analitis terutama adalah metode Point system.

Metode evaluasi jabatan dengan mengikuti hierarchi dalam skema organisasi merupakan cara yang paling sederhana. Bobot/nilai jabatan ditentukan berdasarkan pada jenjang yang tergambar dalam struktur organisasi. Metode ini akan mengundang terusiknya konsep keadilan dalam penggajian dan cenderung merangsang munculnya ketidakpuasan. Motode forced ranking disebut pula dongan istilah konsensus yang menentukan urut-urutan bobot/nilai jabatan berdasarkan kesepakatan oleh sojumlah kecil pejabat dalam organisasi. Proses penentuan jenjang jaba tan dan kelas-kelas yang telah disepakati tentunya berjalan dengan alot dan tegang. Ada kecenderungan bahwa setiap orang yang terlibat da lam musyawarah berkehendak mo nempatkan jabatannya pada posis atas. Metode klasifikasi jabatan merupakan cara yang sudah lobih 
maju daripada metode konsensus. Pada klasifikasi jabatan ini telah disusun kriteria untuk menempatkan jabatan sesuai urutan (rank) tertentu. Kriteria yang dibangun masih bersifat kua-litatif dan naratif yang menjelaskan secara ringkas semua karakteristik jabatan dan persyaratan yang harus dipenuhi oleh para pejabatnya. Me-tode factor comparison bekerja ber-dasarkan faktor-faktor jabatan yang diperbandingkan. Faktor jabatan yang dipilih berkisar 4 sampai 6 seperti tuntutan : mental, keterampilan, fisik/jasmani, lingkungan tempat kerja, dan tanggung jawab. Setiap faktor diberikan nilai angka yang menunjukan derajad kepentingan. Berdasarkan angka total yang diperoleh setiap pekerjaan inilah dapat disusun peringkat jabatan. Metode yang dipergunakan pegawai negeri (sipil/ ABRI) dalam menentukan bobot jabatan berdasarkan tingkat pendidikan formal dan pengalaman (masa) kerja. Walaupun metode ini diterima oleh pegawai tetapi cenderung tidak memacu prestasi/karya terbaik.

\section{Evaluasi Jabatan Kantor}

Metode analitis disebut juga kuantitatif merupakan cara menentukan urutan jabatan didasarkan pada faktor-faktor yang ada pada suatu jabatan atau terkait erat dengannya yang akan dijadikan tolok ukut, proses analitis dan pembuatan uraian jabatan. Cara analitis akan menekan faktor subyektifitas dan menghindari debat yang tidak mendasar. Metode analitis yang paling populer adalah Point/factor rating (metode angka)

Mengingat pekerjaan kantor memiliki ciri-ciri yang khusus seperti diungkapkan oleh Littlefield dan Rachel : (1) more mental work usually required-more" hard to measure; (2) greater variability of work from case to case: (3) numerous small, low volume task not thought to justify standards: and (4) irregularity of work flour of much office work (The Liang Gie. 2000 : 36). Berdasarkan ciri menonjol pekerjaan kantor yang sulit diukur. menuntut banyak kegiatan mental. volumenya kecil dan sejenisnya maka metode angka dinilai paling cocok dalam menilai jabatan terkait dengan penentuan gaji. Hal ini selaras dengan saran yang disampaikan oleh The American Association of Industrial Management (AAIM) yang menyatakan : "Sistem Scores range tidak dirancang untuk pekerjaan yang bersifat manual yang biasanya dikerjakan oleh tenaga keja unskilled atau semiskilled tetapi lebih tepat untuk pekerjaan teknisi. administratif dan penyelia (supervisory) (Achmad S Ruky, 2002: 95) kecocokan pemakaian metode angka untuk menilai jabatan dalam kantor ini secara implisit dikemukakan juga oleh Hani Handoko (1997:173) menyatakan : meskipun pada mulanya sulit cara menyusunnya, tetapi lebih 
tepat dibandingkan metode pembanding faktor karena dapat mempertimbangkan faktor-faktor kritis dengan lebih rinci. Adapun langkahlangkah evaluasi jabatan dengan mempergunakan metode angka (point system) menurut Hani Handoko (1997); Heidjrachman Ranupandojo dan Suad Husnan (1995); Ahmad S Ruky (2002) sebagai berikut :

1. Memilih dan menentukan faktor-faktor kritis;

2. Menentukan tingkatan-tingkatan berbagai faktor

3. Mengalokasikan point pada subfaktor-subfaktor

4. Mengalokasikan points pada semua tingkatan

5. Menyusun manual penilaian; dan

6. Menerapkan Point system

\section{Penutup}

Produktifitas dan efisiensi kerja pegawai harus selalu dapat ditingkatkan. Semua pegawai, tidak terkecuali, khususnya pegawai yang melaksanakan tugas-tugas kantor perlu diarahkan agar mampu memberikan karya terbaik. Oleh karena itu perlu diupayakan munculnya motivasi yang kuat dalam diri pegawai. Salah satu bentuk rangsangan yang mampu membandingkan motivasi kerja adalah pemberian gaji yang layak dan dirasa adil. Hal ini merupakan pekerjaan yang tidak mudah untuk dapat memenuhi harapan seperti ini. Mengingat pekerjaan/jabatan kantor memiliki ciri-ciri yang khusus terutama sulit di-ukur, standarisasi tidak sempurna maka metode yang cocok untuk menentukan tingkatan jabatan adalah Point system. Metode ini dinilai cocok karena mampu mengenai faktor pekerjaan menjadi subfaktor dan derajad dalam setiap jabatan.

\section{Daftar Pustaka}

Achmad S. Ruky. (2002). Manajemen Penggajian dan Pengupahan Untuk Karyawan Perusahaan, Jakarta : PT Gramedia Pustaka Utama.

Hani Handoko T. (1997) Manajemen

Personalia dan Sumber Daya

Manusia, Yogyakarta : BPFE

Heidjrachman Ranupandojo dan

Suad Husnan (1995).

Manajemen Personalia,

Yogyakarta : BPFE

Imam Moedjiono (2002).

Kepemimpinan dan

Keorganisasian, Yogyakarta : UII Press

Kallans, Norman F and B. Lewis Keeling. (1987) Administrative Office Management, Ohio

South -Western Publising Co.

Komaruddin. 1981. Manajemen

Kantor, Bandung : Sinar Baru Mirrian Sjofjan Arif (2000). Kualitas Hidup Kerja Dalam Rangka Menciptakan Kestabilan Organisasi dalam Jurnal 
Bisnis dab Birokrasi, No : $1 N$ ol I/Juli/200, Jakarta : Pasca Sarjana UI

The Liang Gie. (2000) Administrasi Perkantoran Modern, Yogyakarta: Supersukses dan Nur Cahaya.

Quible, Zane K. 1984. Administrative Office Management, Virginia : Reston Publising Company Inc.

\section{Biodata Penulis}

Drs. Joko Kumoro, M.Si. lahir di Purworejo, 26 Juni 1960, lulus strata dua program IImu Administrasi, ISIP UI Jakarta tahun 1997. Dosen Prodi Pendidikan Administrasi Perkantoran /Pendidikan Ekonomi/PDU FIS UNY sejak 1986, pengampu matakuliah Manajemen Perkantoran. 